\title{
Chronic Rhinosinusitis: Time to Revise the Definition and Phenotypes
}

\section{El-Shazly A*}

Department of Otolaryngology and Head and Neck Surgery, Liege University Hospital-CHU, Belgium

*Corresponding author: El-Shazly A, Department of Otolaryngology and Head and Neck Surgery, Liege University Hospital-CHU, Belgium

Received: March 06, 2017; Accepted: March 15, 2017; Published: March 21, 2017

\section{Opinion}

Chronic Rhinosinusitis (CRS) is defined as inflammation of the mucosa lining the paranasal sinuses that lasts more than 12 weeks. Patients with CRS are classified into two subtypes: CRS with nasal polyps (CRSwNP) and CRS without nasal polyps (CRSsNP) [1,2]. However, recent evidences indicate that the inflammation reaches beyond the mucosa of the sinus reaching the underlying bones as part of the disease process. Moreover, accumulating evidences indicate the involvement of special molecular events in patients with allergic rhinitis and CRS, pointing to a distinct $\mathrm{T}_{\mathrm{H} 2}$ pathway driven sinusitis. These findings alert us to consider revising the definition of CRS and to include allergic CRS as a distinct phenotype in the classification of CRS.

Patients with CRS are radiologically assessed with Computed Tomography (CT) scans that often reveal areas of increased bone density and irregular thickening of the sinus walls. This could explain the recurrence of the mucosal disease after surgical treatment and may indicate that these osteitic lesions act as the source of the chronic inflammation with worse baseline measures of disease severity and inflammation [3-7]. Other investigators found that the incidence of osteitis reaches $64 \%$ in patients with recalcitrant CRS [8].

Patients who suffer from allergic rhinitis are also prone to develop CRS. Here, the cytokine profile is biased towards $\mathrm{T}_{\mathrm{H} 2}$ profile indicating a distinct immunological picture. Our group has shown evidence of osteitis in CRS patients with allergic rhinitis and confirmed the presence of a higher grade osteitis in CRS patients without allergy. There was a higher grade of mucosal inflammation over bone inflammation in both CRS groups. However, there was no correlation between the grade of bone and mucosal inflammation in each studied group [9].

At the mucosal level we also showed differences in the magnitude and role of inflammatory cells recruitment to the nasal tissue of CRS patients with or without allergy $[10,11]$. For example, we showed that NK cells infiltrated the epithelial layers of nasal tissue only in CRS patients with allergic rhinitis and not in CRS patients without allergy or controls. NK cells were also more numerous in the stroma of the nasal tissue from CRS patients with allergic rhinitis compared with CRS patients with no allergy or controls. This is due to CX3CR1-ligand interaction on $\mathrm{NK}$ cells, as a result of the $\mathrm{T}_{\mathrm{H} 2}$ induced immunological response. On the other hand, another study demonstrated a novel neuroimmune axis involving eosinophil recruitment in CRS patients with allergic rhinitis through CRTH2/Vasoactive Intestinal Peptide (VIP) \& PGD2 interaction. This further supports a specific type of eosinophilic inflammation in CRS patients with allergic rhinitis. This should not be confused with other distinct phenotypes such as eosinophilic CRS [12].

From the above mentioned evidences it is believed that rhinologists should consider the inflammation of CRS as an inflammatory process that can extend beyond the mucous membrane. The term Allergic Chronic Rhinosinusitis (ACRS) may be included in the classification of CRS as one of the main groups. This will facilitate a proper management plan for this one disease with several different phenotypes.

\section{References}

1. Meltzer EO, Hamilos DL, Hadley JA, Lanza DC, Marple BF, Nicklas RA, et al. Rhinosinustis: developing guidance for clinical trials. J Allergy Clin Immunol. 2006; 118: 17-61.

2. Fokkens W, Lund V, Mullo J. European position paper on rhinosinusitis and nasal polyps 2007. Rhinol Suppl. 2007; 20: 1-136.

3. Perloff JR, Gannon FH, Bolger WE, Montone KT, Orlandi R, Kennedy DW. Bone involvement in sinusitis: An apparent pathway for the spread of disease. Laryngoscope. 2000; 110: 2095-2099.

4. Lee JT, Kennedy DW, Palmer JN, Feldman M, Chiu AG. The incidence of concurrent osteitis in patients with chronic rhinosinusitis: A clinicopathological study. Am J Rhinol. 2006; 20: 278-282.

5. Kennedy DW, Senior BA, Gannon FH, Mantone KT, Hwang P, Lanza DC. Histology and histomorphometry of ethmoid bone in chronic rhinosinusitis. Laryngoscope. 1998; 108: 502-507.

6. Renato J, Giacchi MD, Richard A, Lebowitz MD. Histopathologic evaluation of the ethmoid bone in chronic sinusitis. Am J Rhinol. 2001; 15: 193-197.

7. Bhandarkar ND, Mace JC, Smith TL. The impact of osteitis on disease severity measures and quality of life outcomes in chronic rhinosinusitis. Int Forum Allergy Rhinol. 2001; 1: 372-378.

8. Georgalas C, Videler W, Freling N, Fokkens W. Global osteitis scoring scale and chronic rhinosinusitis: A marker of revision surgery. Clin Otolaryngol. 2010; 35: 455-461.

9. Mutijima E, Delvenne P, El-Shazly AE. Osteitis in chronic rhinosinusitis: a histopathological study of human ethmoid bone remodeling in allergic versus non-allergic chronic rhinosinusitis. Advances in Cellular and Molecular Otolaryngology. 2014, 2: 23504.

10. El-Shazly AE, Begon DY, Kustermans G, Arafa M, Dortu E, Henket M, et al. Novel association between vasoactive intestinal peptide and $\mathrm{CRTH} 2$ receptor in recruiting eosinophils: a possible biochemical mechanism for allergic eosinophilic inflammation of the airways. JBC. 2013; 288: 1374-1384.

11. El-Shazly AE, Doloriert HC, Bisig B, Lefebvre PP, Delvenne P, Jacobs N. A novel cooperation between CX3CL1 and CCL26 inducing NK cell chemotaxis via CX3CR1: A possible mechanism for NK cells infiltration to the allergic nasal tissue. Clin and Exp Allergy. 2013; 43: 322-331.

12. Shah SA, Ishinaga H, Takeuchi K. Pathogenesis of eosinophilic chronic rhinosinusitis. J Inflamm (Lond). 2016; 13: 11.
Austin J Otolaryngol - Volume 4 Issue 1 - 2017

ISSN : 2473-0645 | www.austinpublishinggroup.com

El-Shazly. (C) All rights are reserved
Citation: El-Shazly A. Chronic Rhinosinusitis: Time to Revise the Definition and Phenotypes. Austin J Otolaryngol. 2017; 4(1): 1088 